Article

\title{
In Situ Water Electrolyzer Stack for an Electrobioreactor
}

\author{
Georgy Givirovskiy ${ }^{1, *(\mathbb{D}}$, Vesa Ruuskanen ${ }^{1}$, Leo S. Ojala ${ }^{2}$ and Petteri Kokkonen ${ }^{2}$ \\ and Jero Ahola 1 iD \\ 1 School of Energy Systems, LUT University, P.O. Box 20, FI-53851 Lappeenranta, Finland; \\ vesa.ruuskanen@lut.fi (V.R.); jero.ahola@lut.fi (J.A.) \\ 2 VTT Technical Research Centre of Finland Ltd., P.O. Box 1000, 02044 VTT, Espoo, Finland; \\ leo.ojala@vtt.fi (L.S.O.); petteri.kokkonen@vtt.fi (P.K.) \\ * Correspondence: georgy.givirovskiy@lut.fi; Tel.: +358-50-470-6727
}

Received: 18 April 2019; Accepted: 15 May 2019; Published: 18 May 2019

\begin{abstract}
Hydrogen-oxidizing bacteria provide a sustainable solution for microbial protein production. Renewable electricity can be used for in situ water electrolysis in an electrobioreactor. The use of cultivation medium as the electrolyte enhances the hydrogen dissolution to the medium. This paper proposes a stack structure for in situ water electrolysis to improve the productivity of the electrobioreactor. The hydrogen production rate and the energy efficiency of the prototype stack are analyzed.
\end{abstract}

Keywords: in situ water electrolysis; microbial protein; hydrogen-oxidizing bacteria; electrobioreactor

\section{Introduction}

The intensive use of fossil fuels has resulted in the depletion of natural resources, increasing levels of greenhouse gas emissions, and undesired climate changes. The generation of electrical energy from abundant renewable energy sources, such as wind and solar energy, provides a sustainable and environmentally friendly alternative to fossil-fuel-based energy [1]. However, the intermittent nature of solar and wind energy sources requires the development of efficient and flexible methods for energy storage [2]. Moreover, in order to deal with the challenge of climate change, there is an urgent need for efficient technologies that are capable of capturing and using carbon. One emerging strategy that might significantly contribute to the transition towards a renewable energy-based economy is the microbial assimilation of carbon. This method enables the fixation of abundantly available atmospheric $\mathrm{CO}_{2}$ and its further use as a source of carbon for carbonaceous products and energy carriers by means of microorganisms [3-5].

Considering various microorganisms, autotrophic aerobic hydrogen-oxidizing bacteria (HOB) have been found to be among the most prospective candidates to exploit the potential of renewable energy generation. The distinctive feature of HOB is that they can be grown in a mineral medium containing low amounts of citrate as a minor source of organic carbon, using atmospheric or point source $\mathrm{CO}_{2}$ as the source of carbon along with $\mathrm{H}_{2}$ and $\mathrm{O}_{2}$, which act as the electron donor and the electron acceptor, respectively, for the production of new cellular materials [6]. The intrinsic premier product of $\mathrm{CO}_{2}$ assimilation by $\mathrm{HOB}$ is biomass, the content of which can be tuned to be rich in carbohydrates, proteins, or fatty acids. Thus, HOB have the potential to play a significant role in future sustainable food production systems [7].

The obtained microbial biomass is frequently referred to as a single cell protein (SCP) also known as a microbial protein (MP) because of its high crude protein content of approximately $70-75 \%$ [8]. Volova et al. [9] found that the biological value of proteins synthesized by different strains of HOB 
is sufficient for them to be considered as a potential protein source for human and animal nutrition. The feasibility of $\mathrm{CO}_{2}$ assimilation by $\mathrm{HOB}$ has recently been proven on a pilot scale within the framework of the Power-to-Protein project in Belgium. A pilot plant produces an MP with a targeted capacity of 1-2 kg per day using $\mathrm{HOB}$ with $\mathrm{H}_{2}$ and $\mathrm{O}_{2}$ produced by water electrolysis and $\mathrm{CO}_{2}$ and $\mathrm{NH}_{3}$ recovered from a wastewater treatment plant [10]. Polyhydroxybutyrate (PHB) is another possible bio-based product, which can be derived from $\mathrm{CO}_{2}$ assimilation by $\mathrm{HOB}[6,11]$. Interestingly, $\mathrm{PHB}$ is a biopolymer and is considered a carbon and energy storage material in bacteria. A wide variety of important platform chemicals can be derived from PHB including thermoplastic, methyl-esterified 3-hydroxybutyrate oligomers, R-3-hydroxybutyric acid, 1,3-butandiol (BDO), crotonic acid, acetoacetic acid, and some others [12].

The low solubility of the main reactant gases $\mathrm{H}_{2}, \mathrm{O}_{2}$, and $\mathrm{CO}_{2}$ in the aqueous solution where the $\mathrm{HOB}$ cells are being suspended drastically decreases the mass transfer and overall process efficiency [12]. The highest reported average $\mathrm{H}_{2}$-to-biomass conversion efficiencies are up to $80 \%$ in continuous operation and up to $65 \%$ in the sequence batch reactor [11]. To overcome this constraint, there is increasing scientific interest in combining water electrolysis and $\mathrm{CO}_{2}$ assimilation by $\mathrm{HOB}$ into a single vessel, which is called a hybrid biological-inorganic (HBI) system. This provides an advantage of improved gas transfer of $\mathrm{H}_{2}$ and $\mathrm{O}_{2}$ to the liquid phase over the conventional gas fermentation process with an external supply of main reactant gases. The concept was successfully proven on a laboratory scale by Pamela A. Silver and Daniel G. Nocera's research group. For instance, Torella et al. [13] reported a development of integrated bioelectrochemical systems in which HOB was used to convert $\mathrm{CO}_{2}$ into biomass and fuel alcohols at high efficiencies using scalable earth-abundant catalysts. In subsequent studies, Liu et al. [14] developed a hybrid water splitting-biosynthetic system based on CO-based catalysts possessing unique self-healing properties, which made it possible to achieve a $\mathrm{CO}_{2}$ reduction efficiency above $50 \%$ and a solar-to-chemical efficiency of almost $10 \%$ when coupled with the existing photovoltaic systems. A hybrid inorganic-biological system and the same biocompatible catalysts were used to fix $\mathrm{CO}_{2}$ and $\mathrm{N}_{2}$ into $\mathrm{NH}_{3}$ and a biofertilizer in the studies of [15] and for biomass synthesis from $\mathrm{CO}_{2}$ in the studies of [16].

After successful proof-of-concept of $\mathrm{CO}_{2}$ assimilation by $\mathrm{HOB}$ using the $\mathrm{HBI}$ systems, the scientific focus shifted towards the objectives of enhanced energy efficiency, product selectivity, and scaling up [17]. The development of a robust, efficient, and ergonomic reactor system designed with in situ electrolysis of the cultivation medium for the HBI process is considered one of the key research directions in this field. The main requirements for such a design are the following: (i) the system has to be biocompatible; (ii) the system must have an acceptable electrode surface-to-volume ratio, and (iii) the system components must be low cost and have long-term stability [18]. Other main limitations of the HBI systems are the low conductivity of the cultivation medium, an increase in the ohmic losses, and the current density limitations set by the microorganisms. In the traditional alkaline and proton exchange membrane (PEM) electrolyzers, the electrolytic cells are series connected to form a stack structure with a high efficiency and a compact design [19]. Thus, the electrolyzer stack structure has not been reported to be applied to HBI systems.

The purpose of this study is to develop and present a conceptual design of an electrobioreactor to enable upscaling of the HBI process to an industrial scale and to discuss the main aspects affecting the energy efficiency of the system. To reach these targets, a novel in situ water electrolyzer stack structure for an electrobioreactor is introduced to enhance the hydrogen production rate and energy efficiency of HOB cultivation. The performance of the in situ electrolyzer stack is experimentally studied. Further, the achievable energy efficiency and the volumetric hydrogen production rate are discussed based on the cell model.

This paper is organized as follows: Section 2 describes the principles of HOB production with in situ water electrolysis. The in situ water electrolyzer stack prototype is introduced and the experimental results are discussed in Section 3 and in Section 4, respectively. Finally, Section 5 concludes the paper. 


\section{Theory and Concept Background}

To date, all reported bioelectrochemical systems (BES) have been studied at volumes ranging from $100 \mathrm{~mL}$ to $1 \mathrm{~L}$ by applying simplified electrode configurations [5,13-16]. This leads to the conclusion that the BES design technology is currently in its infancy. This section aims to provide a possible conceptual design for a scaled-up prototype for the BES by first defining the special characteristics of in situ water electrolysis and the BES, then describing the design idea, and finally, proving and testing the concept on an experimental scale.

\subsection{In Situ Water Electrolysis and Electrobioreactor Characteristics}

While the technical performance and energy efficiency of the electrobioreactors are crucial aspects that have to be taken into consideration in the design stage, water electrolysis can be considered one of the major phenomena that affects those criteria. The minimum thermodynamic potential required for water electrolysis, called reversible voltage, is $1.23 \mathrm{~V}$ under standard ambient conditions. Without auxiliary heat, the required minimum voltage is higher and is dependent on the electrolysis conditions (e.g., $1.43 \mathrm{~V}$ under standard ambient conditions). From the perspective of energy efficiency, the voltage driving the electrolysis should thus be kept as low as possible. The actual voltage required to drive the electrolysis is higher because of overvoltages (i.e., voltage losses) caused by the impedance between the electrodes and the activation reactions. Hence, the overall cell voltage is the sum of different overvoltages (overpotentials), as presented in the following equation:

$$
U_{\text {cell }}=U_{\text {rev }}+U_{\mathrm{ohm}}+U_{\mathrm{act}}+U_{\mathrm{con}}
$$

where $U_{\text {cell }}$ is the cell voltage, $U_{\text {rev }}$ is the reversible open circuit voltage, $U_{\text {ohm }}$ is the overvoltage caused by ohmic losses in the cell elements, $U_{\text {act }}$ is the activation overvoltage caused by electrode kinetics, and $U_{\text {con }}$ is the concentration overvoltage caused by the mass transport processes [20].

There are several crucial parameters that describe the water electrolysis process. First of all, the production of hydrogen can be estimated according to Faraday's laws of electrolysis. The hydrogen production rate $(\mathrm{NL} / \mathrm{h})$ is directly proportional to the electric charge transferred at the electrodes and can be expressed as

$$
f_{\mathrm{H}_{2}}=\eta_{\mathrm{F}} \frac{N_{\text {cell }} i_{\text {cell }} A_{\text {cell }}}{z F} 22.41 \frac{\mathrm{NL}}{\mathrm{mol}} 3600 \frac{\mathrm{s}}{\mathrm{h}^{\prime}},
$$

where $z$ is the number of moles of electrons transferred in the reaction (for hydrogen, $z=2$ ), $F$ is the Faraday constant $\left(9.6485 \times 10^{4} \mathrm{C} / \mathrm{mol}\right), N_{\text {cell }}$ is the number of cells constituting the electrolyzer stack, $i_{\text {cell }}$ is the current density $\left(\mathrm{A} / \mathrm{cm}^{2}\right), A_{\text {cell }}$ is the effective cell area $\left(\mathrm{cm}^{2}\right)$, and $\eta_{F}$ is the Faraday efficiency, also known as the current efficiency.

Secondly, the specific energy consumption $E_{\mathrm{s}}\left(\mathrm{kWh} / \mathrm{Nm}^{3}\right)$ of an electrolysis process, which relates the energy consumed to produce hydrogen, can be obtained from

$$
E_{\mathrm{s}}=\frac{\int_{0}^{t} N_{\text {cell }} i_{\text {cell }} A_{\text {cell }} U_{\text {cell }} \mathrm{d} t}{\int_{0}^{t} f_{\mathrm{H}_{2}} \mathrm{~d} t},
$$

where $f_{\mathrm{H}_{2}}$ is the hydrogen flow rate in $\mathrm{Nm} / \mathrm{h}^{3}$.

Finally, the electrolyzer stack efficiency can be calculated based on the higher heating value (HHV), which is the minimum energy required to produce hydrogen gas by a thermoneutral process. The per volume unit HHV of hydrogen gas is $3.54 \mathrm{kWh} / \mathrm{Nm}^{3}$, which can be assumed to represent the energy consumption of the process with a $100 \%$ efficiency. Thus, the electrolyzer efficiency can be described by the following equation:

$$
\eta_{\mathrm{E}}=\frac{\mathrm{HHV}_{\mathrm{H}_{2}}}{E_{\mathrm{s}}} 100 \% .
$$


On the other hand, the particularity of the process itself is definitely yet another dominating aspect in the design development of the HBI system. Due to the fact that both $\mathrm{H}_{2}$ and $\mathrm{O}_{2}$ are important for $\mathrm{CO}_{2}$ fixation by $\mathrm{HOB}$, a simplified design that does not require expensive separation of anode and cathode compartments is possible for this process. The application of an electrolyzer without a separator facilitates the operation and maintenance of the system while reducing the capital costs. Furthermore, a simplified construction eliminates the internal resistance and therefore the ohmic overpotential related to the separator. However, the main source of ohmic overpotential is the $\mathrm{pH}$-neutral electrolyte with a relatively low conductivity which is typically used in HBI systems.

One notable constraint of the HBI process is the incidental formation of toxic reactive oxygen species (ROS) on the cathode side, represented by superoxide, hydrogen peroxide, and hydroxyl radicals, at and below potentials required for the $\mathrm{H}_{2}$ evolution reaction [17]. This phenomenon can be mitigated by using biocompatible ROS-resistant catalysts. For instance, a cobalt-phosphorous (CoP) alloy cathode, which kinetically favors $\mathrm{H}_{2}$ generation, was used in combination with a self-healing cobalt-phosphate anode to enhance the production rate and achieve high solar-to-fuel and solar-to-biomass energy efficiencies in the studies of [14]. Distinctive advantages of the aforementioned catalysts include (i) biocompatibility; (ii) low overpotentials required for water splitting; (iii) low cost as a result of the use of earth-abundant materials as raw materials, and (iv) ease of manufacture by electrodeposition into a variety of conventional substrate materials, such as stainless steel or nickel sheets.

\subsection{Immersed Electrodes}

So far, the bioelectrochemical systems for the above-mentioned microbial protein production have used simple rod or plate electrodes immersed inside the bioreactor tank. Figure 1 shows the progress of a typical BES cultivation with a small-scale ( $60 \mathrm{~mL}$ liquid volume) bioreactor with immersed rod electrodes (for the details of the cultivation, the reader is referred to Appendix A.1). The hydrogen concentration at the BES exhaust is also presented.

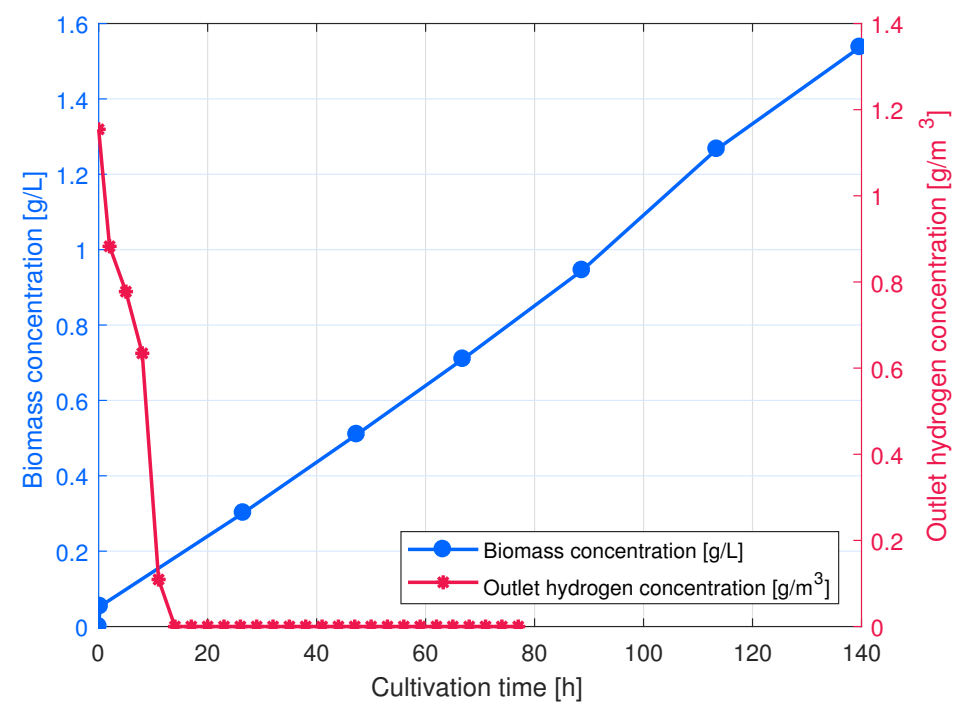

Figure 1. BES cultivation of Cupriavidus necator H16 with immersed electrodes, compared with the hydrogen concentration at the bioreactor gas outlet.

The first points in Figure 1 correspond to a situation before inoculation, i.e., a $0 \mathrm{~g} / \mathrm{L}$ biomass and a $1.15 \mathrm{~g} / \mathrm{m}^{3}$ hydrogen concentration at the outlet. The hydrogen evolution rate before the inoculation was $5.3 \times 10^{-7} \mathrm{~kg} / \mathrm{h}$. The theoretical hydrogen evolution rate based on the electrolysis current was $6.8 \times 10^{-7} \mathrm{~kg} / \mathrm{h}$, and therefore, the current efficiency of the hydrogen generation was $78 \%$. Very soon after the beginning of the cultivation, the $\mathrm{H}_{2}$ concentration decreased below the detection limit, and the 
biomass grew at a constant rate, as the growth was limited by the availability of the produced $\mathrm{H}_{2}$. Therefore, the hydrogen utilization rate was close to $100 \%$, which is considerably higher than the gaseous $\mathrm{H}_{2}$ utilization rate of $80 \%$ cited by [11]. During the first $12 \mathrm{~h}$ of cultivation, before the hydrogen evolution rate started to limit the growth, the hydrogen utilization ratio increased at an exponential rate. This rate was assumed to be comparable with the biomass growth rate (see Appendix A.2). From the hydrogen data, the specific growth rate of the biomass was estimated to be $0.14 \mathrm{~h}^{-1}$. Previously, for instance in the study by Yu and Munasinghe (2018) [21], similar specific growth rates have been reported for the autotrophic growth of Cupriavidus necator: $0.094-0.12 \mathrm{~h}^{-1}$ under different gaseous $\mathrm{H}_{2}$ pressures.

The main issues related to the electrodes immersed in the reactor tank are as follows:

- The electrode area must be increased to maximize the hydrogen production.

- The coil-shaped electrodes inside each other lead to inhomogeneous current densities in the electrode surface and the electrolyte.

- The rod electrodes also force most of the current to travel along an unnecessarily long path through the low-conductivity electrolyte.

- The electrodes make the mixing of the reactor more difficult.

- The internal resistance of the electrode limits the length and thus the surface area of the electrode.

- The serial connection of the immersed electrodes is not allowed to avoid excessive leakage currents, although it would be necessary to scale the system voltage to a favorable level for the industrial-scale AC/DC converters

These aspects can be addressed by applying a stack structure for water electrolysis.

\subsection{Conceptual Design of the Electrobioreactor System}

The integration of electrodes inside the bioreactor, while keeping the structure compact and ergonomic, is a challenging engineering task. Despite the lack of information about possible BES designs, outstanding progress has been achieved in alkaline and PEM water electrolyzer stack designs. Mimicking stack structure designs and integrating them into the electrobioreactor could provide significant benefits for increasing the energy efficiency and overall technical performance of the system. For that reason, our research team proposes the following electrobioreactor design concept with an external in situ water electrolyzer stack (Figure 2).

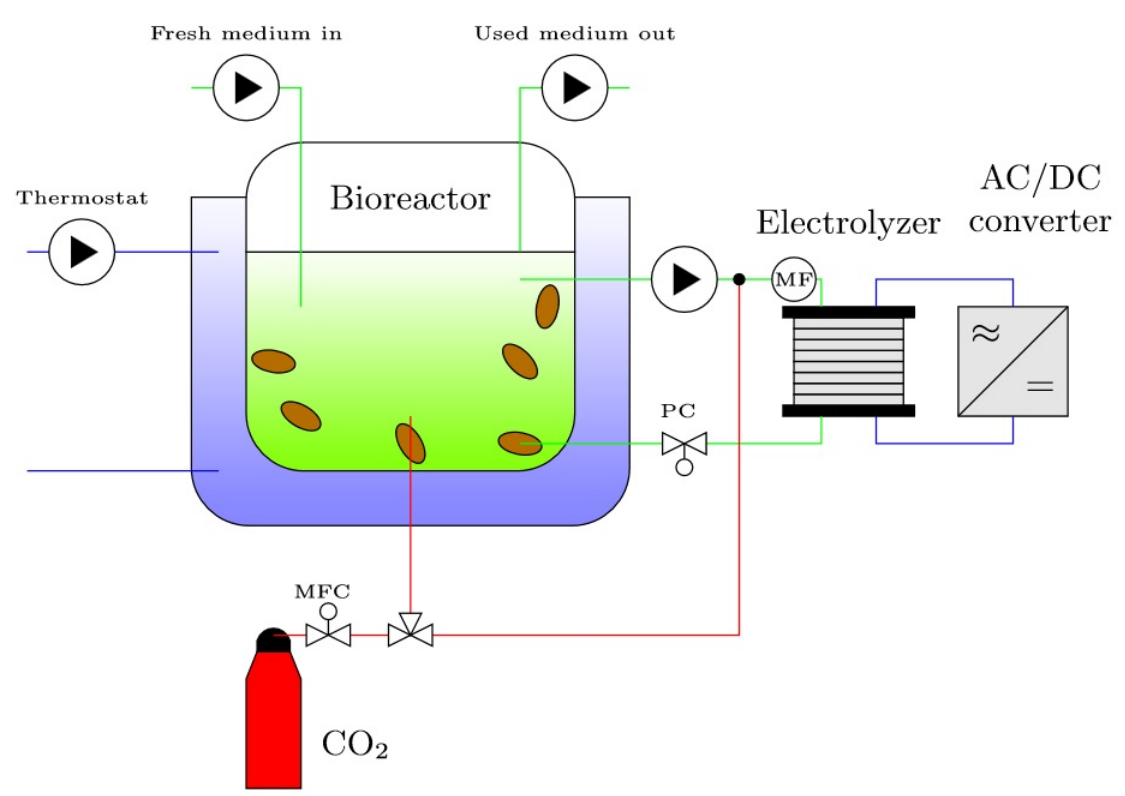

Figure 2. Proposed process diagram of the electrobioreactor with an external electrolyzer stack for the hybrid biological-inorganic (HBI) process. 
It can be clearly seen from the process diagram that the electrode stack assembly is not immersed in the cultivation medium, but the cultivation medium is constantly circulating through the external stack where the water electrolysis takes place. The microbes are allowed to flow through the electrolyzer stack, thereby increasing the total volume used for the microbial growth. If the microbes were not allowed to enter the electrolyzer, for example, because of the current density being too high for the microbes, a porous separator could be used to prevent microbes from entering the electrolyzer part of the system. A Nafion 117 proton-exchange membrane was used to separate the anode and cathode compartments of the bioelectrochemical reactor in [5]. However, a careful design would be required to avoid the separator blocking up because of the microbes.

The electrodes in the stack operate in a bipolar mode acting as an anode from one side and as a cathode from the other side. Depending on the electrode function, each side can be coated with a suitable catalyst material by performing electrodeposition prior to $\mathrm{CO}_{2}$ assimilation by the HOB. The medium flows between the electrodes in a flow channel formed by the nonconducting separator plates. No separator is needed to separate hydrogen and oxygen gases, contrary to the traditional alkaline electrolyzer stack, as both gases can be dissolved in the bioreactor cultivation medium [22]. Any type of conventional bioreactor can be used to perform stirring, the control of the main process parameters, such as a $\mathrm{CO}_{2}$ supply, and for other important operations required for $\mathrm{HOB}$ cultivation. The proposed system design enables achievement of the following:

- A high electrode area per volume;

- A constant distance between electrodes, leading to constant current densities;

- Simple series connection of electrolytic cells;

- Low leakage currents, resulting in enhanced power densities;

- Stack voltage levels suitable for industrial AC/DC converters;

- A high energy efficiency.

\section{Materials and Methods}

\subsection{Experimental Setup}

Figure 3a illustrates the experimental setup used for the electrolysis tests, consisting of an external manifold with simple hosing to enable parallel electrolyte flow, a pump to provide constant circulation of the medium through the system, a vessel for the medium input and output, and an electrolyzer stack. The electrolyzer stack is schematically presented in Figure $3 \mathrm{~b}$. The stack consists of series-connected bipolar electrodes (uncoated $316 \mathrm{~L}$ stainless steel with a thickness of $1 \mathrm{~mm}$ ) separated by tubular plastic (PVC) spacers and end plates made of stainless steel acting both as a current collector and a pressure plate. The effective electrode area of each circular electrode is $86.6 \mathrm{~cm}^{2}$, with a diameter of $10.5 \mathrm{~cm}$. The distance between the electrodes is $10 \mathrm{~mm}$, and there are ten cells connected in series. The current is supplied using a standard cable shoe to the connector bolt welded to the end plate. The stack structure is compressed with insulated tightening rods assembled through the corner holes of the pressure plates. The hosing providing the parallel electrolyte flow of the cells is made from plastic (PVC) tube with a diameter of $6 \mathrm{~mm}$. The measurement system control and data logging were implemented in a LabVIEW environment. Current was supplied and measured with a Sorensen DLM (40 V/15 A) laboratory power source with a current stability of $7.5 \mathrm{~mA}$. The stack and cell voltages were measured with a Keithley 2701 data acquisition system with a voltage measurement accuracy of $0.015 \%$ for reading and $0.006 \%$ for the $100 \mathrm{~V}$ range. A Grundfos Alpha2 25-60 household hot water circulation pump with an integrated frequency converter was used to pump the electrolyte. Tests were performed at room temperature. The temperatures of the manifold inlet and outlet flows were measured with PT100 thermistors with an IPAQ-C201 mA-signal transmitter. The mA signal was further read with a NI-9208 C series current input module. 


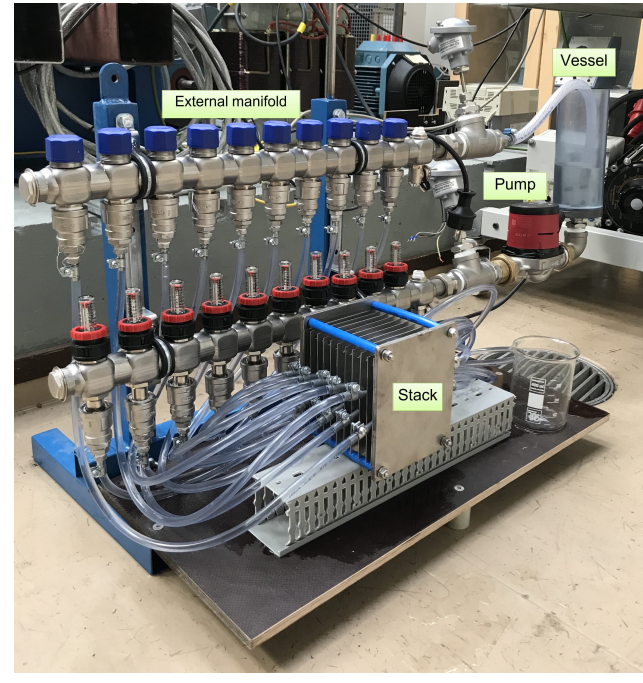

(a) Experimental setup

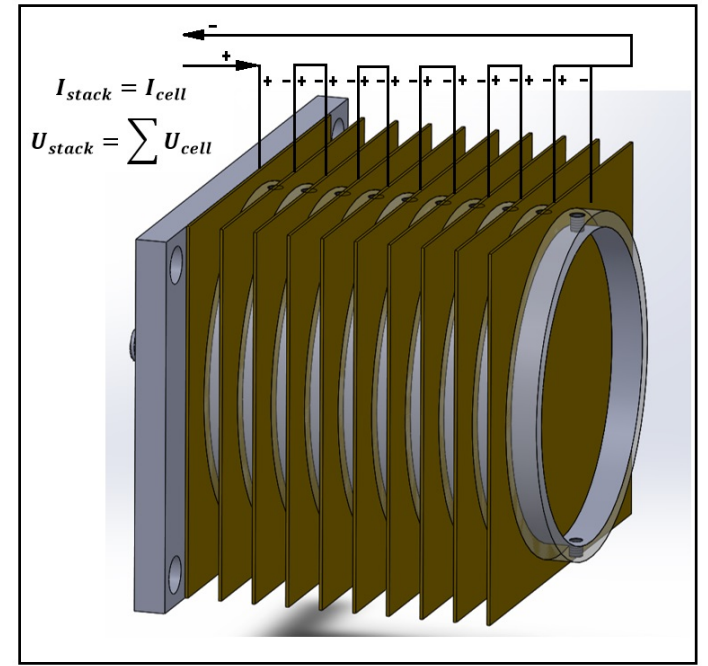

(b) Electrolyzer stack

Figure 3. Experimental setup used for the electrolysis tests and a schematic of the electrolyzer stack. The ten cells are electrically connected in series, and the electrolyte flow is equally divided between the parallel cells by the manifolds.

\subsection{Electrolyte}

The mineral medium used for the cultivation of HOB is based on Leibniz-Institut DSMZ growth medium number 81 [23] with the following changes: (i) The major chloride compounds were replaced with the corresponding sulfates to minimize the production of chlorine gas by the electrolysis current. The trace element solution SL-6 of Pfennig [24] used in the medium preparation was left unchanged both for the sake of convenience and because some bacteria might require chloride as a micronutrient, especially at high salt concentrations [25]. (ii) The ferric ammonium citrate concentration was reduced to $5 \mathrm{mg} / \mathrm{L}$ from the $50 \mathrm{mg} / \mathrm{L}$ recommended by DSMZ to prevent iron precipitation from the medium during storage of even a few days. (iii) $\mathrm{Na}_{2} \mathrm{SO}_{4}$ was added to increase the electrical conductivity of the medium and reduce the required electrolysis voltage. The final mineral medium composition was $2.3 \mathrm{~g} / \mathrm{L} \mathrm{KH}_{2} \mathrm{PO}_{4}, 2.9 \mathrm{~g} / \mathrm{L} \mathrm{Na}_{2} \mathrm{HPO}_{4} \cdot 2 \mathrm{H}_{2} \mathrm{O}$, $5.45 \mathrm{~g} / \mathrm{L} \mathrm{Na}_{2} \mathrm{SO}_{4}, 1.19 \mathrm{~g} / \mathrm{L}\left(\mathrm{NH}_{4}\right)_{2} \mathrm{SO}_{4}, 0.5 \mathrm{~g} / \mathrm{L} \mathrm{MgSO}_{4} \cdot 7 \mathrm{H}_{2} \mathrm{O}, 11.7 \mathrm{mg} / \mathrm{L} \mathrm{CaSO}{ }_{4} \cdot 2 \mathrm{H}_{2} \mathrm{O}, 4.4 \mathrm{mg} / \mathrm{L}$ $\mathrm{MnSO}_{4} \cdot \mathrm{H}_{2} \mathrm{O}, 5 \mathrm{mg} / \mathrm{L} \mathrm{NaVO}_{3}$ (metavanadate), $0.5 \mathrm{~g} / \mathrm{L} \mathrm{NaHCO}_{3}, 5 \mathrm{mg} / \mathrm{L}$ ferric ammonium citrate $(16 \% \mathrm{Fe}), 0.5 \mathrm{mg} / \mathrm{L} \mathrm{ZnSO}_{4} \cdot 7 \mathrm{H}_{2} \mathrm{O}, 1.5 \mathrm{mg} / \mathrm{L} \mathrm{H}_{3} \mathrm{BO}_{3}, 1 \mathrm{mg} / \mathrm{L} \mathrm{CoCl}_{2} \cdot 6 \mathrm{H}_{2} \mathrm{O}, 0.05 \mathrm{mg} / \mathrm{LCuCl}_{2} \cdot 2 \mathrm{H}_{2} \mathrm{O}$, $0.1 \mathrm{mg} / \mathrm{L} \mathrm{NiCl}_{2} \cdot 6 \mathrm{H}_{2} \mathrm{O}, 0.15 \mathrm{mg} / \mathrm{L} \mathrm{Na}_{2} \mathrm{MoO}_{4} \cdot 2 \mathrm{H}_{2} \mathrm{O}$. The medium had a $\mathrm{pH}$ of 7 and a conductivity of $12 \mathrm{mS} / \mathrm{cm}$.

\section{Results and Discussion}

Figure $4 \mathrm{a}$ depicts the measured currents as a function of time with various voltages ranging from $30 \mathrm{~V}$ to $39 \mathrm{~V}$ during $1 \mathrm{~h}$ of experimental time. The stack voltage as a function of stack current is presented in Figure $4 \mathrm{~b}$, and the cell voltage as a function of current density is shown in Figure 4c.

The main parameters of the electrolyzer stack efficiency were calculated based on the collected current-voltage relationships. Figure 5 a presents the hydrogen production rate and the electrical supply power as a function of the stack current density. Figure $5 b, c$ shows the specific energy consumption and the electrolyzer efficiency as a function of the stack current density. The values of the aforementioned parameters are summarized in Table 1. 


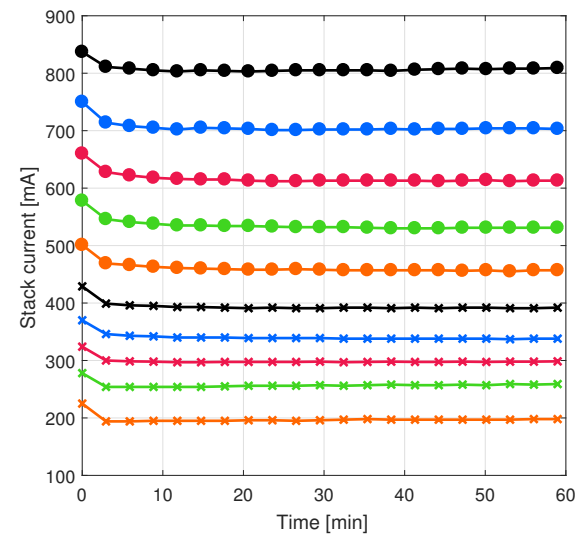

(a)

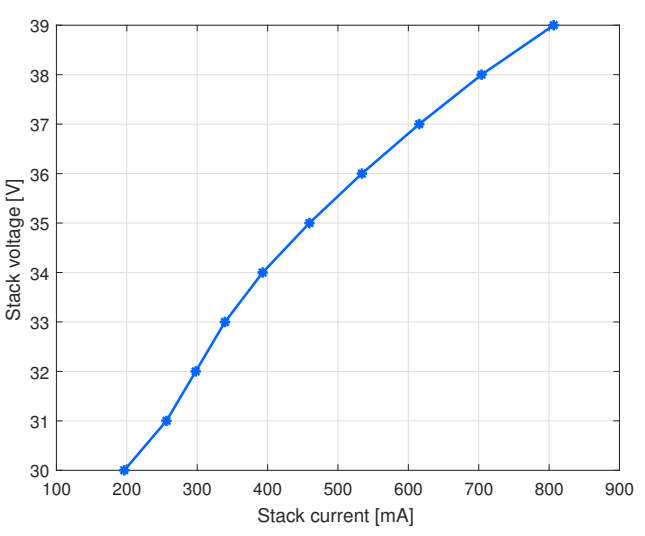

(b)

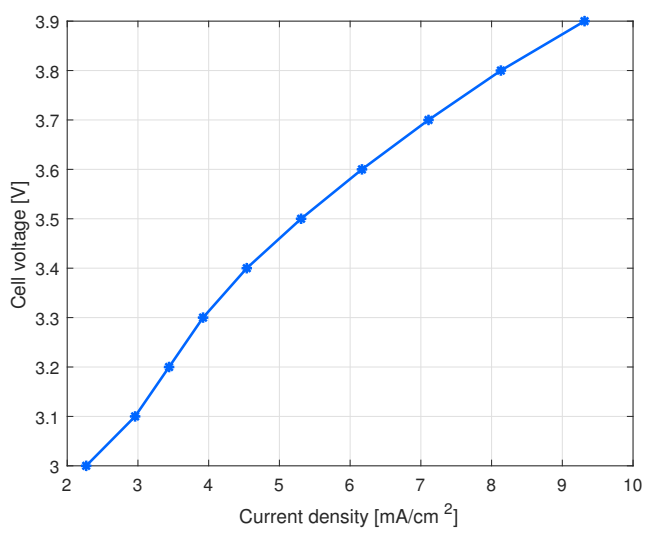

(c)

Figure 4. Measured currents and current densities of the electrolyzer stack with various supply voltages. (a) Measured currents as a function of time with various voltages; (b) stack voltage as a function of stack current; (c) cell voltage as a function of current density.

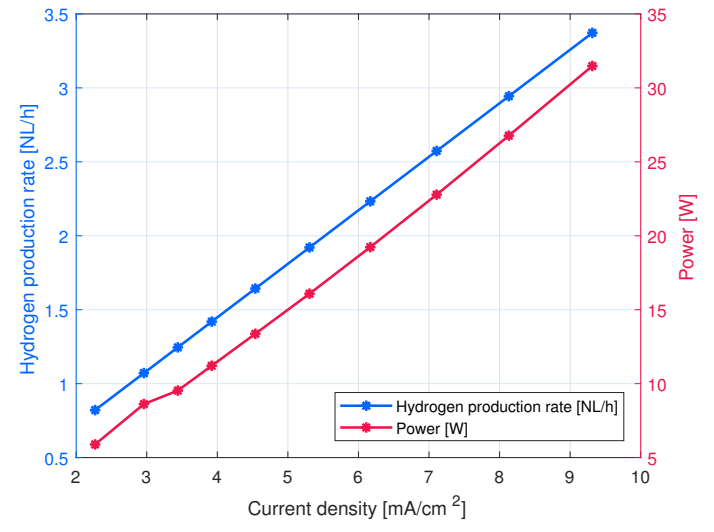

(a) Hydrogen production rate and power

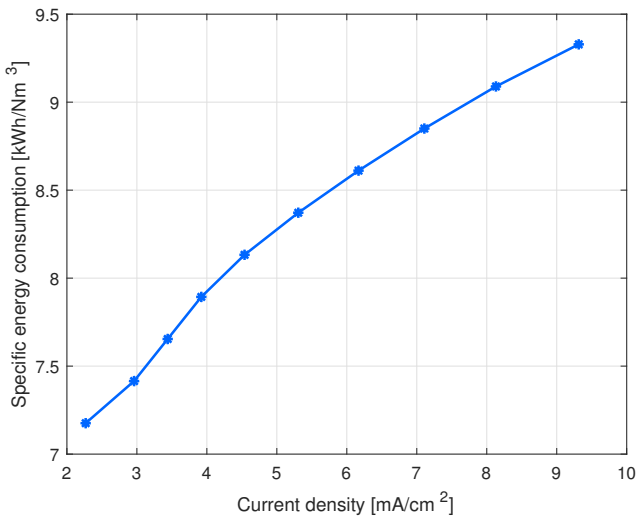

(b) Specific energy consumption

Figure 5. Cont. 


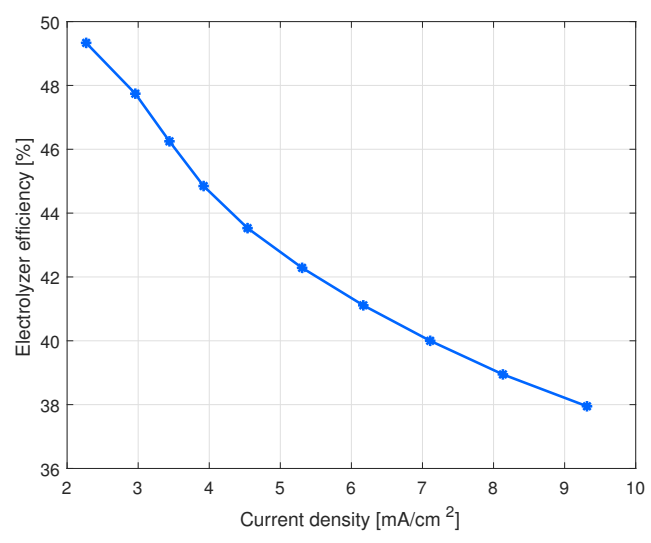

(c) Electrolyzer efficiency (higher heating value, $\mathrm{HHV}$ )

Figure 5. Main energy efficiency parameters of the electrolyzer stack.

Table 1. Main energy efficiency parameters of the electrolyzer stack calculated based on the measured stack voltage and current.

\begin{tabular}{ccccc}
\hline $\begin{array}{c}\boldsymbol{U}_{\text {stack }} \\
{[\mathbf{V}]}\end{array}$ & $\begin{array}{c}\boldsymbol{I}_{\text {stack }} \\
{[\mathbf{A}]}\end{array}$ & $\begin{array}{c}f_{\mathbf{H}_{2}} \\
{[\mathbf{N L} / \mathbf{h}]}\end{array}$ & $\begin{array}{c}\boldsymbol{E}_{\mathbf{s}} \\
{\left[\mathbf{k W h} /\left(\mathbf{N ~ m}^{3}\right)\right]}\end{array}$ & $\begin{array}{c}\eta_{\mathrm{E}, \mathrm{HHV}} \\
{[\%]}\end{array}$ \\
\hline 30 & 0.20 & 0.82 & 7.18 & 49.33 \\
31 & 0.26 & 1.07 & 7.42 & 47.74 \\
32 & 0.30 & 1.25 & 7.65 & 46.25 \\
33 & 0.34 & 1.42 & 7.89 & 44.85 \\
34 & 0.39 & 1.64 & 8.13 & 43.53 \\
35 & 0.46 & 1.92 & 8.37 & 42.29 \\
36 & 0.53 & 2.23 & 8.61 & 41.11 \\
37 & 0.62 & 2.57 & 8.85 & 40.00 \\
38 & 0.70 & 2.94 & 9.09 & 38.95 \\
39 & 0.81 & 3.37 & 9.33 & 37.95 \\
\hline
\end{tabular}

\subsection{Effect of Electrode Distance on the Cell Performance}

As was stated in Section 2, the efficiency of the HOB cultivation process can be enhanced by reducing the electric power consumption during the water electrolysis process. According to Equation (1), the overall cell potential is the sum of different overpotentials, one of which is the ohmic overpotential, representing the electrical resistance of the cell elements. We may state that the ohmic overpotential is mainly caused by the voltage loss across the cultivation medium with a low conductivity. Consequently, a reduction in space between the electrodes in the stack substantially decreases the electrical resistance and leads to elevated current densities at the same cell potentials. Having measured the current and voltage data of the electrobioreactor electrolyzer stack with a $10 \mathrm{~mm}$ distance between the electrodes, the corresponding data were calculated for the same stack with a $3 \mathrm{~mm}$ distance between the electrodes, according to the simplified cell voltage model published in [26] and presented by the following equation:

$$
U_{\text {cell }}=U_{\text {rev }}+\frac{\delta_{\mathrm{m}} i_{\text {cell }}}{\sigma_{\mathrm{m}}}+\alpha \operatorname{arcsinh}\left(\frac{i_{\text {cell }}}{2 i_{0}}\right),
$$

where $\delta_{\mathrm{m}}$ is the distance between the electrodes in $(\mathrm{cm}), \sigma_{\mathrm{m}}$ is the conductivity of the medium in $(\mathrm{S} / \mathrm{cm}), \alpha$ is the charge transfer coefficient for the anode and the cathode separately, and $i_{\mathrm{o}}$ is the exchange current density on the electrode surfaces.

The modeling results of the stack current densities as a function of cell voltage with a $10 \mathrm{~mm}$ and $3 \mathrm{~mm}$ distance between the electrodes are illustrated in Figure 6a. Figure 6b shows the hydrogen production rate and the power as a function of stack current density. Figure $6 \mathrm{c}$ depicts the specific 
energy consumption as a function of the stack current density for the electrolyzer stack with a $3 \mathrm{~mm}$ distance between the electrodes.

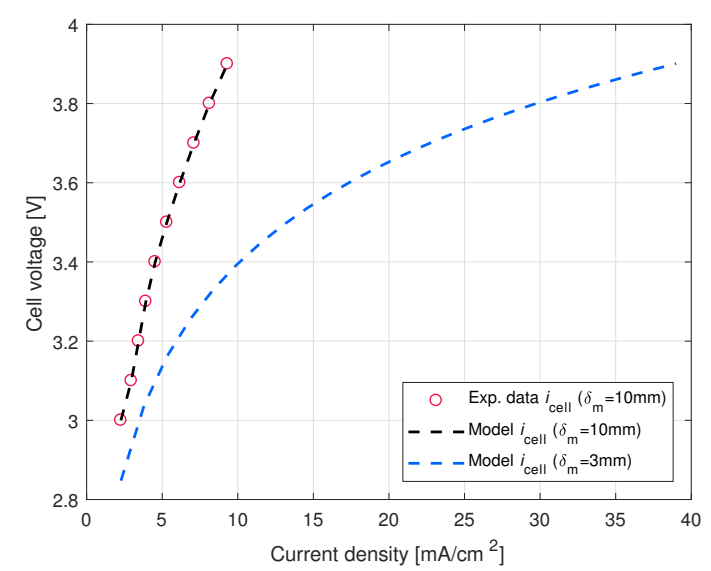

(a)

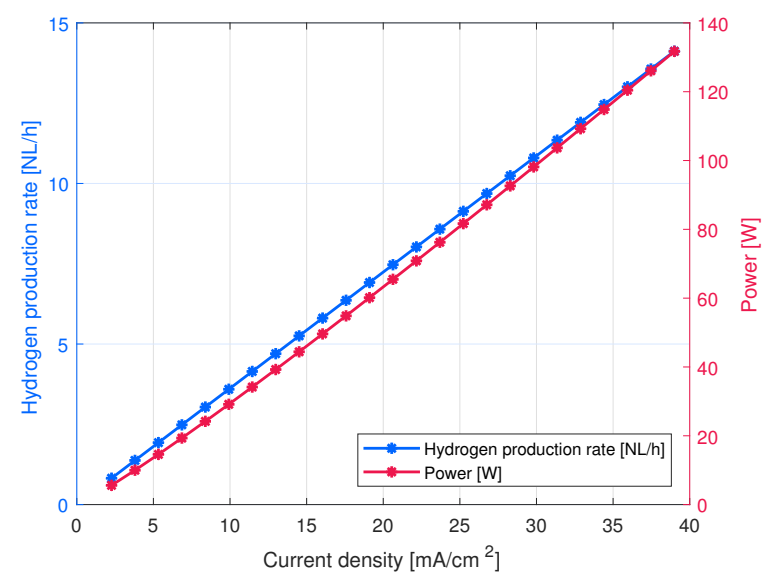

(b)

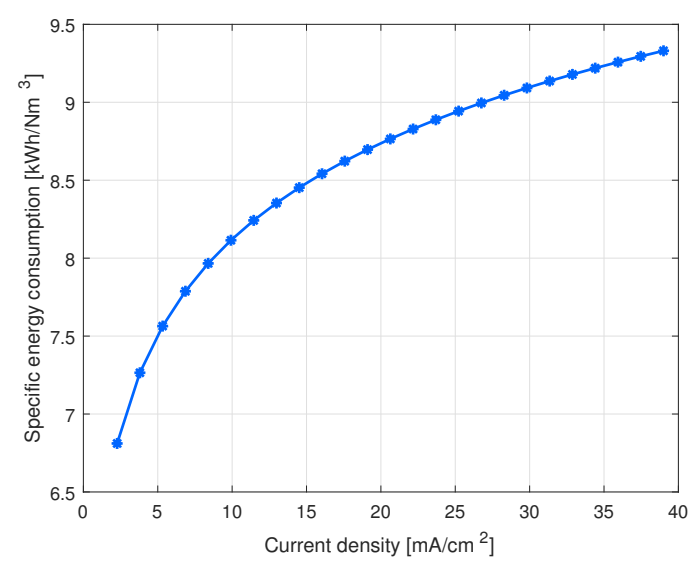

(c)

Figure 6. The main energy efficiency parameters of the electrolyzer stack with a decreased distance between the electrodes. (a) Cell voltage as a function of current density at variable electrode separations; (b) hydrogen production rate and supply power as a function of current density with a $3 \mathrm{~mm}$ distance between the electrodes; (c) specific energy consumption as a function of the current density with a $3 \mathrm{~mm}$ distance between the electrodes.

\subsection{Volumetric Productivity}

As an example, a bioreactor with a volume of $1000 \mathrm{~L}$ with a specific production rate of $0.2 \mathrm{~g} /(\mathrm{Lh})$ would produce $200 \mathrm{~g}$ of biomass per hour. With the $2.5 \mathrm{~g} / \mathrm{mol}$ biomass yield from hydrogen, the hydrogen consumption is $80 \mathrm{~mol} / \mathrm{h}$. If CoP-coated electrodes are used, a $50 \% \mathrm{HHV}$ efficiency can be reached with current densities up to $5 \mathrm{~mA} / \mathrm{cm}^{2}$ [26]. According to (2), the required cell area is $85.8 \mathrm{~m}^{2}$. By assuming that there are 100 circular cells in series and that the total axial length of the cell is $5 \mathrm{~mm}$, the electrolyzer volume is $429 \mathrm{~L}$. Thus, it can be stated that with coated electrodes, the electrolyzer volume is roughly half of the bioreactor volume, and in the case of noncoated stainless steel electrodes, the bioreactor and electrolyzer volumes are roughly the same. This leads to the fact that the actual bioreactor tank might not be needed at all, or, at least, the size could be significantly reduced, as the electrolyzer stack structure provides a significant proportion of the volume required for microbial growth. 


\section{Conclusions}

Hydrogen production for $\mathrm{HOB}$ cultivation in an electrobioreactor with in situ water electrolysis was studied. A stack structure was introduced to enhance hydrogen production compared with reactor tank-immersed electrodes. The energy efficiency of the prototype stack was experimentally studied. It was found that with a water electrolysis energy efficiency (HHV) of 50\%, the current density could be up to a range of $5 \mathrm{~mA} / \mathrm{cm}^{2}$ with coated electrodes. Thus, the volume of the in situ water electolyzer stack is approximately half of the total volume required for microbial cultivation. However, the results are based on the energy efficiency of the water electrolysis process, and the maximum allowed current density that does not harm microbial growth has not been studied yet.

Author Contributions: Conceptualization, G.G., V.R., L.S.O., P.K. and J.A.; methodology, G.G., V.R., L.S.O., and P.K.; software, G.G. and V.R.; formal analysis, G.G. and V.R.; investigation, G.G., L.S.O. and V.R.; writing-original draft preparation, G.G. and V.R.; writing—review and editing, L.S.O., P.K. and J.A.; project administration, V.R. and J.A.

Funding: Financial support was given by the Technology Industries of Finland Centennial Foundation and Jane and Aatos Erkko Foundation for the project "Feed and food from carbon dioxide and electricity-research and piloting of the future protein production."

Conflicts of Interest: The authors declare no conflict of interest. The funders had no role in the design of the study; in the collection, analyses, or interpretation of data; in the writing of the manuscript, or in the decision to publish the results.

\section{Appendix A. Materials and Methods}

\section{Appendix A.1. BES Cultivation}

The HOB strain used in the BES cultivation was Cupriavidus necator H16 (DSM 428) supplied by the Leibniz-Institut DSMZ_-Deutsche Sammlung von Mikroorganismen und Zellkulturen GmbH. The inoculum for the BES cultivation was grown in $20 \mathrm{~mL}$ liquid volume shake flasks under $12.5 \%$ $\mathrm{H}_{2}, 13.1 \% \mathrm{O}_{2}, 25 \% \mathrm{CO}_{2}$, and $49.4 \% \mathrm{~N}_{2}$ for nine days. The BES cultivation was performed in a small-scale ( $60 \mathrm{~mL}$ liquid volume) bioreactor with immersed rod electrodes (cathode: stainless steel, anode: iridium-oxide-coated titanium). The reactor was supplied with gaseous $\mathrm{CO}_{2}$ and a constant electrolysis current of $18 \mathrm{~mA}$. The bioreactor was jacketed, and the cultivation temperature was kept constant at $30^{\circ} \mathrm{C}$ with external water circulation. Prior to the inoculation, reactors filled with a sterile growth medium were allowed to stabilize to the temperature, electrolysis, and $\mathrm{CO}_{2}$ purge conditions for $2 \mathrm{~h}$. The first data point was recorded at the end of the stabilizing period before inoculation. The BES reactor was inoculated with an appropriate volume of inoculum $(2 \mathrm{~mL})$ to get an initial optical density of 0.2 units for the cultivation broth. Subsequently, the optical density (OD) at $600 \mathrm{~nm}$ was measured daily by withdrawing samples of $1 \mathrm{~mL}$ from the reactor. The OD was correlated with the cell density by measuring the dry cell density at the end of the cultivation period from an aliquot of $2 \mathrm{~mL}$. The biomass in the aliquot was separated by centrifugation, washed twice with pure water (Milli-Q Advantage A10 Water Purification system by Millipore), and finally, the biomass was dried at $105^{\circ} \mathrm{C}$. The correlation between the OD and the dry cell density was found to be $1 \mathrm{OD}$ unit $=0.255 \mathrm{~g} / \mathrm{L}$ biomass. During the BES cultivation, the hydrogen concentration at the reactor gas exhaust was measured with a Pfeiffer Vacuum Omnistar GDS 301 gas analysis system. Before cultivation, the Omnistar was calibrated against the known $\mathrm{H}_{2}$ concentration of $10 \%$ in a reference gas supplied by AGA.

\section{Appendix A.2. HOB Growth Rate Calculation from the Outlet Hydrogen Concentration Data}

For the HOB biomass growth rate determination, the hydrogen concentration at the bioreactor outlet was transformed into a hydrogen utilization ratio:

$$
\mathrm{H}_{2} \text { Utilization }=\frac{\mathrm{c}_{\mathrm{H}_{2}}^{\text {Out,Initial }}-\mathrm{c}_{\mathrm{H}_{2}}^{\text {Out }}}{\mathrm{c}_{\mathrm{H}_{2}}^{\text {Out,Initial }}},
$$


where $\mathrm{c}_{\mathrm{H}_{2}}^{\text {Out }}$ is the hydrogen concentration at the reactor outlet, and $\mathrm{c}_{\mathrm{H}_{2}}^{\text {Out,Initial }}$ is the concentration at the beginning of cultivation. The use of $\mathrm{H}_{2}$ was assumed to increase at the same rate as the biomass growth. A generic exponential function was fitted to the increasing range (between $0.5 \mathrm{~h}-12 \mathrm{~h}$ ) of the $\mathrm{H}_{2}$ utilization data:

$$
\mathrm{H}_{2} \text { Utilization }=A e^{\mu t},
$$

where $A$ is a pre-exponential constant, and $\mu$ is the rate constant. The best fit was achieved with $A=0.1675$ and $\mu=0.1422 \mathrm{~h}^{-1}$. Because the biomass growth is dependent on the hydrogen consumption, the rate constant can be considered an approximation of the biomass growth rate. The $\mathrm{H}_{2}$ utilization data and the fitted curve are shown in Figure A1.

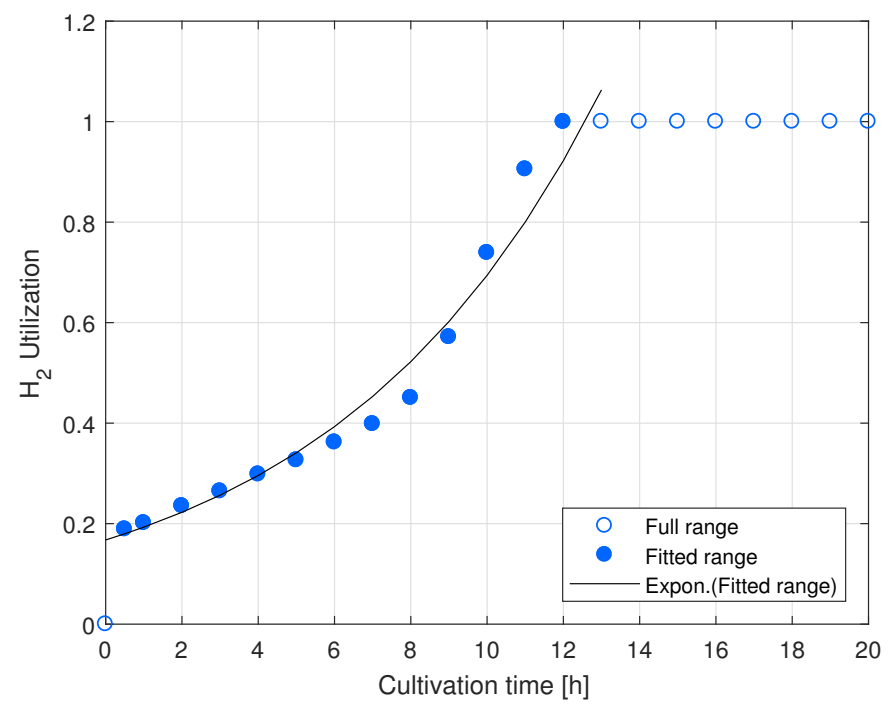

Figure A1. Development of hydrogen utilization in the small-scale BES. The exponential curve fitted to the part of the data range is associated with exponential biomass growth.

\section{References}

1. Brown, T.W.; Bischof-niemz, T.; Blok, K.; Breyer, C.; Lund, H.; Mathiesen, B.V. Response to 'Burden of proof: A comprehensive review of the feasibility of $100 \%$ renewable-electricity systems. Renew. Sustain. Energy Rev. 2018, 92, 834-847. [CrossRef]

2. Kousksou, T.; Bruel, P.; Jamil, A.; El Rhafiki, T.; Zeraouli, Y. Energy storage: Applications and challenges. Sol. Energy Mater. Sol. Cells 2014, 120, 59-80. [CrossRef]

3. Vidal, F.; Koponen, J.; Ruuskanen, V.; Bajamundi, C.; Kosonen, A.; Simell, P.; Ahola, J.; Frilund, C.; Elfving, J.; Reinikainen, M.; et al. Power-to- $X$ technology using renewable electricity and carbon dioxide from ambient air: SOLETAIR proof-of-concept and improved process concept. J. $\mathrm{CO}_{2}$ Util. 2018, 28, 235-246.

4. Pikaar, I.; Matassa, S.; Rabaey, K.; Bodirsky, B.L.; Popp, A.; Herrero, M.; Verstraete, W. Microbes and the Next Nitrogen Revolution. Environ. Sci. Technol. 2017, 51, 7297-7303. [CrossRef]

5. Kracke, F.; Wong, A.B.; Maegaard, K.; Deutzmann, J.S.; Hubert, M.A.; Hahn, C.; Jaramillo, T.F.; Spormann, A.M. Robust and biocompatible catalysts for efficient hydrogen-driven microbial electrosynthesis. Commun. Chem. 2019, 2, 45. [CrossRef]

6. Matassa, S.; Boon, N.; Verstraete, W. Resource recovery from used water: The manufacturing abilities of hydrogen-oxidizing bacteria. Water Res. 2015, 68, 467-478. [CrossRef] [PubMed]

7. Linder, T. Making the case for edible microorganisms as an integral part of a more sustainable and resilient food production system. Food Secur. 2019. [CrossRef]

8. Pikaar, I.; Vrieze, J.D.; Rabaey, K.; Herrero, M.; Smith, P.; Verstraete, W. Science of the Total Environment Carbon emission avoidance and capture by producing in-reactor microbial biomass based food, feed and slow release fertilizer: Potentials and limitations. Sci. Total. Environ. 2018, 644, 1525-1530. [CrossRef] [PubMed] 
9. Volova, T.G.; Barashkov, V.A. Characteristics of proteins synthesized by hydrogen-oxidizing microorganisms. Appl. Biochem. Microbiol. 2010, 46, 574-579. [CrossRef]

10. Oesterholt, F.; Matassa, S.; Palmen, L.; Roest, K.; Verstraete, W. Pilot scale production of single cell proteins using the power-to-protein concept Future global challenges. In Proceedings of the 2nd International Resource Recovery Conference, New York, NY, USA, 5-9 August 2018; pp. 1-16.

11. Matassa, S.; Verstraete, W.; Pikaar, I.; Boon, N. Autotrophic nitrogen assimilation and carbon capture for microbial protein production by a novel enrichment of hydrogen-oxidizing bacteria. Water Res. 2016, 101, 137-146. [CrossRef]

12. Yu, J. Bio-based products from solar energy and carbon dioxide. Trends Biotechnol. 2014, 32, 5-10. [CrossRef] [PubMed]

13. Torella, J.P.; Gagliardi, C.J.; Chen, J.S.; Bediako, D.K.; Colón, B.; Way, J.C.; Silver, P.A.; Nocera, D.G. Efficient solar-to-fuels production from a hybrid microbial-water-splitting catalyst system. Proc. Natl. Acad. Sci. USA 2015, 112, 2337-2342. [CrossRef] [PubMed]

14. Liu, C.; Ziesack, M.; Silver, P.A. Water splitting-biosynthetic system with $\mathrm{CO}_{2}$ reduction efficiencies exceeding photosynthesis. Science 2016, 352, 1210-1213. [CrossRef] [PubMed]

15. Liu, C.; Sakimoto, K.K.; Colón, B.C.; Silver, P.A.; Nocera, D.G. Ambient nitrogen reduction cycle using a hybrid inorganic-biological system. Proc. Natl. Acad. Sci. USA 2017, 114, 6450-6455. [CrossRef]

16. Liu, C.; Colón, B.E.; Silver, P.A.; Nocera, D.G. Solar-powered $\mathrm{CO}_{2}$ reduction by a hybrid biological|inorganic system. J. Photochem. Photobiol. A Chem. 2018, 358, 411-415. [CrossRef]

17. Nangle, S.N.; Sakimoto, K.K.; Silver, P.A.; Nocera, D.G. Biological-inorganic hybrid systems as a generalized platform for chemical production. Curr. Opin. Chem. Biol. 2017, 41, 107-113. [CrossRef]

18. Krieg, T.; Sydow, A.; Schro, U.; Schrader, J.; Holtmann, D. Reactor concepts for bioelectrochemical syntheses and energy conversion. Trends Biotechnol. 2014, 32, 645-655. [CrossRef] [PubMed]

19. Decourt, B.; Lajoie, B.; Debarre, R.; Soupa, O. The Hydrogen-Based Energy Conversion FactBook; The SBC Energy Institute: Melbourne, Australia, 2014.

20. Ursúa, A.; Gandía, L.; Sanchis, P. Hydrogen Production From Water Electrolysis: Current Status and Future Trends. Proc. IEEE 2012, 100, 410-426. [CrossRef]

21. Yu, J.; Munasinghe, P. Gas Fermentation Enhancement for Chemolithotrophic Growth of Cupriavidus necator on Carbon Dioxide. Fermentation 2018, 4, 63. [CrossRef]

22. Reilly, C.O.; Farrell, M.; Harvey, D.; Cassidy, J. Operation of an inexpensive bipolar alkaline electrolyser producing a mix of $\mathrm{H}_{2} / \mathrm{O}_{2}$ fuel. Int. J. Hydrogen Energy 2015, 41, 2197-2201. [CrossRef]

23. DSMZ GmbH. 81. Mineral Medium For Chemolithotrophic Growth (H-3); DSMZ: Braunschweig, Germany, 2011.

24. Pfennig, N. Rhodopseudomonas globiformis, sp. n., a new species of the Rhodospirillaceae. Arch. Microbiol. 1974, 100, 197-206. [CrossRef]

25. Roeßler, M.; Sewald, X.; Müller, V. Chloride dependence of growth in bacteria. FEMS Microbiol. Lett. 2006, $225,161-165$.

26. Givirovskiy, G.; Ruuskanen, V.; Ojala, L.; Lienemann, M.; Kokkonen, P.; Ahola, J. Electrode material studies and cell voltage characteristics of the in situ water electrolysis performed in a pH-neutral electrolyte in bioelectrochemical systems. Heliyon 2019, 5, e01690. [CrossRef]

(C) 2019 by the authors. Licensee MDPI, Basel, Switzerland. This article is an open access article distributed under the terms and conditions of the Creative Commons Attribution (CC BY) license (http://creativecommons.org/licenses/by/4.0/). 